\section{Comparative analysis of glucose-6-phosphate dehydrogenase levels in pre-term and term babies delivered at University of Ilorin Teaching Hospital}

\author{
Temitope Olorunsola Obasa, \\ Omotayo Olukemi Adesiyun, \\ Olugbenga Ayodeji Mokuolu, \\ Ayodele Isaac Ojuawo
}

Neonatal Intensive Care Unit, University of Ilorin Teaching Hospital, Ilorin, Nigeria

\section{Abstract \\ Glucose-6-phosphate (G6P) is an enzyme} in the hexose monophosphate shunt required for the production of reducing equivalents needed to mop up free radicals. thereby keeping hemoglobin in its free state. Deficiency of the enzyme can cause severe neonatal jaundice. The aim of this study was to compare G6PD levels in pre-term and term babies, and evaluate the extent to which G6PD deficiency determines the severity of jaundice in various gestational age groups. Samples of cord blood collected from consecutively delivered babies in the University of Ilorin Teaching Hospital, Nigeria, were assayed for G6PD levels, and the babies were observed for jaundice during the first week of life. Those who developed jaundice had serial serum bilirubin measured. Nine hundred and thirty-three babies had G6PD assayed, with 348 being G6PD deficient, giving a hospital based prevalence of $37.3 \%$. Of the 644 who were followed up, 143 (22.2\%) were pre-term and 501(77.8\%) were term babies. Babies with gestational age (GA) 27-29 weeks had the highest G6PD levels. However, there was no significant variation among the different gestational age groups $(\mathrm{F}=0.64, \mathrm{P}=0.64)$. Jaundice occurred more in pre-term compared to term babies with a relative risk of $2.41 \quad\left(\chi^{2}=60.95, \mathrm{P}=0.00001\right)$. Occurrence of jaundice in pre-term babies was irrespective of G6PD status $\left(\chi^{2}=0.2\right.$, $\mathrm{P}=0.66, \mathrm{RR}=1.09, \mathrm{CI}=0.83<\mathrm{RR}<1.43)$. There is an inverse relationship between gestational age and the occurrence of jaundice $\left(R^{2}=-\right.$ 0.874). Pre-term babies are more likely to have higher G6PD levels, but occurrence of jaundice in pre-term babies is irrespective of G6PD status. More severe jaundice (especially for gestational age) occurring in pre-term babies requires critical care.

\section{Introduction}

Glucose-6-phosphate dehydrogenase (G6PD) is an enzyme in the hexose monophosphate shunt that catalyzes the oxidation of glucose-6-phoshate to 6-phosphogluconate while concomitantly reducing the oxidised form of nicotinamide adenide dinucleotide phosphate (NADP+) to NADPH. ${ }^{1}$ The $\mathrm{NADPH}$, a required co-factor in many biosynthetic reactions, maintains glutathione in its reduced form. Reduced glutathione acts as a scavenger for free radicals, and thus helps reduce oxidized hemoglobin to free hemoglobin; otherwise oxidized hemoglobin will precipitate as Heinze bodies.2,3

G6PD deficiency is the most common enzymopathy-producing disease in humans. ${ }^{1}$ Inherited as an $\mathrm{X}$-linked recessive disorder, it affects about 400 million people worldwide. ${ }^{3}$ In Nigeria, an estimated $22 \%$ of the male population is said to have G6PD deficiency. ${ }^{4}$ In neonates in Nigeria, figures in jaundiced babies range from $35.3 \% 5$ to $61.5 \% 6$.

Studies from this part of the world repeatedly show that babies with G6PD deficiency develop worse forms of jaundice that require exchange transfusions, or that may even lead to kernicterus. ${ }^{5-10}$ There is, however, no documentation correlating enzyme levels with gestational age. Therefore, this study aims to compare the G6PD levels in pre-term and term babies, and the effect of their enzyme levels on the severity of jaundice.

\section{Materials and Methods}

This cross sectional prospective study was carried out aon the Labor ward and the Neonatal Intensive Care Unit of the University of Ilorin Teaching Hospital (UITH), Nigeria, with the approval of the institutional Ethical Review Committee. Average yearly admissions range from 4,500-5,000 babies, with virtually all babies being of West African descent.

Consecutively delivered newborn babies were recruited into the study. Exclusion criteria included asphyxia, extravascular blood loss, polycytemia, evidence of septicemia, congenital malformations, babies with GA 42 weeks or over, babies of mothers with blood group 0 Rhesus antigen positive, and exposure to antenatal phenobarbitone.

At delivery, following resuscitation, blood from the placental end of the cut cord was drawn and G6PD levels were assayed using an in vitro diagnostic kit manufactured by RANDOX $\odot$ Laboratories Limited (Co. Antrim, UK). Babies were then classified as appropriate for gestational age (AGA), small for gestational age (SGA) and large for gestational age (LGA)
Correspondence: Temitope 0. Obasa, Department of Paediatrics, University of Ilorin Teaching Hospital, Ilorin, Kwara State, Nigeria.

Tel. +234.803.498.8894.

E-mail: drtopeobasa@gmail.com

Key words: Glucose-6-phosphat deficiency, preterm, term, jaundice.

Acknowledgement: we are grateful to the nursing staff of the labour ward and NICU. We also wish to thank Dr. Olarewaju of the Department of Haematology and Mr. Akinyinka of the Department of Chemical Pathology for their help with analyzing the samples.

Contributions: T00, 00A data collection and entry; OAM data clean up and data analysis; A0 corrected the manuscript.

Conflict of interest: the authors report no conflicts of interest. The authors funded the study themselves.

Received for publication: 17 July 2011

Revision received: 27 November 2011.

Accepted for publication: 30 November 2011.

This work is licensed under a Creative Commons Attribution NonCommercial 3.0 License (CC BYNC 3.0).

(O)Copyright T.O. Obasa et al., 2012

Licensee PAGEPress srl, Italy

Pediatric Reports 2012; 4:e7

doi:10.4081/pr.2012.e7

using the intrauterine growth charts described by Lubchenco, ${ }^{11}$ which are those used in the Neonatal Intensive Care Unit, UITH.

Gestational age was calculated from the last menstrual period (LMP); this remains the gold standard. When LMP was indeterminate, a first trimester ultrasound was used. When gestational age could not be determined by either LMP or first trimester ultrasound, a neurological and physical maturity rating chart (Ballard12 chart) was employed.

Babies were observed on a daily basis for jaundice during the first week of life. Mothers had previously been educated on how to examine for jaundice and on the dangers of neonatal hyperbilirubinemia, and on the importance of avoiding commonly available oxidants, such as naphthalene balls, methyl salicylate containing ointments, local concoctions (most of which are brewed with naphthalene), and a commonly available powder, Moju powder, which contains camphor and is used to cure babies' skin ailments. Mobile phone numbers of the baby's care givers' (preferably the mother's) had been collected and mothers were reminded about their baby's appointment by phone. Some babies remained in the nursery during the duration of the period they needed 
to be followed up as the mothers were still on the ward (e.g. following Caeserian section or following delivery complications).

Serum bilirubin of all babies was analyzed as required for correct management. Babies whose serum bilirubin values were higher than those accepted as normal on the Bhutani normogram ${ }^{13}$ were managed according to the standard protocol of the Neonatal Intensive Care Unit. This is in line with the guidelines set by the American Academy of Pediatrics. 14

\section{Laboratory methods}

For G6PD assay, $2 \mathrm{~mL}$ of blood drawn from the placental end of the cord were collected into EDTA containing bottles within the first hour of delivery. Enzyme level was assayed using a quantitative in vitro test (RANDOX $\odot$ ). Red blood cell G6PD value of $2.9 \mathrm{U} / \mathrm{gHb}$ or over was considered as normal.

Plasma bilirubin (total and conjugated) was determined using the method of Malloy and Evelyn. 15

\section{Data analysis}

Data analysis was carried out using EPI-info version 6 software. ${ }^{16}$ Association between categorical variables was tested using $\chi^{2}$ test. Relationship between a continuous variable and dependent variable were tested using Student's t-test or ANOVA as appropriate.

For all statistical analysis, $\mathrm{P}<0.05$ was considered significant.

\section{Results}

\section{Study population}

The study was conducted over a 10-month period during which there were 4,591 deliveries on the Labor ward of the UITH. There were 2,525 males and 2,066 females with a male to female ratio of 1.1:1. Gestational age of babies ranged from 26 weeks to 44 weeks with a mean of $39 \pm 3.9$ weeks. Birth weight ranged from 700 $5,450 \mathrm{gr}$ with a mean of $3513 \pm 1315.2$ gr. Nine hundred and thirty-three babies had G6PD enzyme assay performed shortly after birth, but 289 were eventually excluded for various reasons, such as early pre-term death, PCV over $64 \%$, full blood count results that eventually were suggestive of sepsis, eventual evidence of extravascular blood loss, babies of blood group 0 Rhesus positive mothers, and incomplete results. Six hundred and forty-four babies were followed up till the end of the study.

The gestational age (GA) of the babies studied ranged from 27-42 weeks with a mean GA of $38 \pm 2.7$ weeks. Five hundred and thirty-six babies (83.2\%) were appropriate for $\mathrm{GA} ; 59$ $(9.2 \%)$ were small for $\mathrm{GA}$, while $49(7.6 \%)$ were large for gestational age.

\section{Glucose-6-phosphate dehydrgenase levels}

Table 1 shows the mean G6PD levels in relation to gestational age. Babies with gestational age between 27-29 weeks had the highest G6PD values $(5.10 \pm 4.99 \mathrm{U} / \mathrm{gHb})$, followed by babies with gestational age (GA) 30-33 weeks $(4.23 \pm 2.5 \mathrm{U} / \mathrm{gHb})$. Post-term babies had the lowest G6PD values of the groups $(3.7 \pm 2.4$ $\mathrm{U} / \mathrm{gHb})$. Overall, there was no statistically significant difference in G6PD levels among the gestational age groups $(\mathrm{F}=0.64, \mathrm{P}=0.64)$.

\section{Prevalence of Jaundice in relation to gestational age}

Eighty-six (61\%) pre-term babies compared to 125 (25\%) term babies developed jaundice (Table 2) and the difference was statistically significant $\left(\chi^{2}=60.95, \mathrm{P}=0.00001, \mathrm{RR}=2.41\right.$, $\mathrm{CI}=1.97<\mathrm{RR}<2.95)$. Pre-term babies were two and half times more likely to develop jaundice as the term newborns. This relationship is further supported by data showing an inverse relationship between gestational age and the development of jaundice (Figure 1). With an $\mathrm{R}^{2}$ of 0.874 , the predictive ability of gestational age indicating the possible occurrence of jaundice was high; it can be predicted with certainty that the younger the gestational age, the more likely it would be for a baby to have jaundice.

\section{Relationship between jaundice and gestational age with respect to glucose-6-phosphate dehydrgenase level}

We analyzed the presence of G6PD deficiency among jaundiced pre-term and term babies (Table 2). Jaundice occurred in 33 (63.5\%) pre-term babies who were G6PD deficient and in $53(58.2 \%)$ of pre-term babies who were G6PD normal $(\mathrm{P}=0.66)$; however, this difference was not statistically significant.

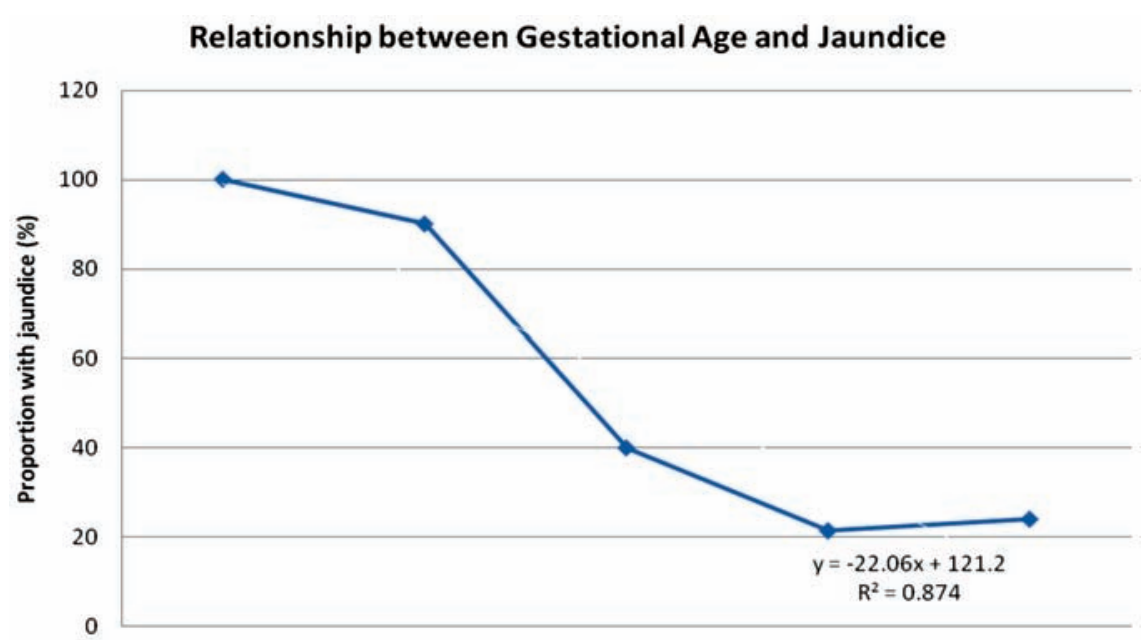

Figure 1. Relationship between gestational age and proportion of babies with jaundice.
Among the term babies, jaundice occurred in 78 (41.5\%) babies who were G6PD deficient but in $47(15 \%)$ of G6PD normal babies; the difference was significantly different $\left(\chi^{2}=24.3\right.$, $\mathrm{P}=0.0000008, \quad \mathrm{RR}=2.25, \quad \mathrm{CI}=1.62<\mathrm{RR}<3.11$ ) developing jaundice being twice that of a G6PD normal term baby.

\section{Treatment of jaundice}

The need to institute treatment for jaundice, and the methods used, was based on the child's morbidities. As is the unit's policy, however, pre-term babies with GA less than 34 weeks by default begin phototherapy within $24 \mathrm{~h}$ of birth. This is a pre-emptive strategy and has been found to reduce the incidence of exchange blood transfusions performed on this set of babies.

Table 3 shows the average duration of phototherapy, and number of exchange blood transfusions for each gestational age group.

Babies with GA between 27-29 weeks spent the longest duration of time under phototherapy. Length of time spent under phototherapy progressively decreased with increasing gestational age and the difference was statistically significant $(\mathrm{F}=123.34, \mathrm{P}=0.000)$.

No baby developed or died from acute bilirubin encephalopathy during this study.

\section{Discussion}

In this study, glucose-6-phosphate dehydrogenase levels were found to be higher in preterm babies than term babies, but this was not statistically significant. A review of the work of other researchers ${ }^{17,18}$ showed that pre-term babies usually have significantly higher G6PD with the chances of a G6PD deficient term baby GA, chronological age in hours and existing co- 
levels. The small cohort of pre-term babies, as compared to the number of term babies, followed up till the end of the study could explain why the higher G6PD levels in pre-term babies were not statistically significant.

A higher G6PD enzyme level in pre-term neonates may be due to the fact that the preterm baby has immature hemopoietic cell lines. ${ }^{19}$ An assay of immature red blood cells would naturally yield higher enzyme levels. ${ }^{20}$

Sixty-one percent of the pre-term babies developed neonatal jaundice compared to $25 \%$ of term babies. This was expected and the difference was statistically significant. These figures are lower than those previously documented in other studies: $71.2 \%{ }^{21}$ and $80 \% 22$ of pre-term babies, and $60 \%{ }^{22}$ of term babies. The pre-term baby is less mature and less able to handle a bilirubin load. Therefore, not only do pre-term babies have a higher level of serum bilirubin for gestational age, but they have jaundice for longer period of time. ${ }^{13,19,22,23}$ The pre-term baby's inability to handle a bilirubin load arises primarily from the immaturity of their conjugating enzyme systems. While the UDPGT activity of a term baby functions at $1 \%$ of adult values, the baby with a GA of under 34 weeks has an UDPGT activity that functions at less than $0.01 \% .24,25 \mathrm{In}$ addition to this, intrauterine meconium accumulation in the gut contains approximately $100-200 \mathrm{mg}$ of bilirubin per $100 \mathrm{~g}$ of meconium at birth, $50 \%$ or more of which is unconjugated. ${ }^{26}$ The immaturity of the pre-term baby's enteric innervations does not permit him to evacuate meconium as early after delivery as the term newborn. Therefore, with the full effect of the enterohepatic circulation, the pre-term baby's bilirubin load increases.

An inverse relationship was observed between gestation age and the presence of jaundice $\left(\mathrm{R}^{2}=0.874\right)$. Jaundice occurred in $100 \%$ of babies whose GA was between 27-29 weeks, with a consistent decline in the slope up till the babies of GA 37-40 weeks. There was a marginal rise in the frequency of occurrence of jaundice in the babies with a GA of 41-42 weeks. As described above, the pre-term baby is expected to develop jaundice more frequently and of greater severity than the term newborn.

The cause of jaundice occurring in the preterm population was probably more a function of their prematurity than of the G6PD deficiency. Clinical jaundice was found to occur in 33 out of $52(63.5 \%)$ of the pre-term babies who were G6PD deficient and in 53 out of 91 (58.2\%) of pre-term babies who were G6PD normal. In term babies, 47 out of 313 (15\%) of the G6PD normal babies developed jaundice, compared with 78 out of 188 (41.5\%) of the G6PD deficient babies. Earlier results from this research have already shown that the earlier pre-term babies are likely to have higher G6PD values. It is, therefore, not surprising that the occurrence of jaundice in the pre-term babies is more a function of their premature status (and thus by implication, immature conjugating systems) than it is of G6PD status.

The lower the baby's gestational age, the longer phototherapy will continue. Babies with GA 27-29 weeks spent an average of $119.5 \pm 50.5 \mathrm{~h}$ on phototherapy, with babies GA 37-40 weeks spending the least number of hours on phototherapy. Despite the fact that the earlier pre-term babies (GA $\leq 33$ weeks) made up only $8.54 \%$ of the study population, they spent the longest time on phototherapy, and this was highly statistically significant $(\mathrm{F}=123.34, \mathrm{P}=0.000)$. The long time spent

under phototherapy by the pre-term babies can be explained by: i) the fact that the unit policy is to start pre-term babies with GA less than 34 weeks on phototherapy, within $24 \mathrm{~h}$ of birth. This policy is founded on local documentation that has shown that this practice reduces the need for exchange transfusions in this set of babies; ii) as discussed above, the pre-term baby is prone to develop a more severe jaundice by virtue of her immaturity. A review of existing literature did not report any comparison between the duration of phototherapy between term and pre-term babies.

No baby developed or died from acute bilirubin encephalopathy during this study.

Table 1. Mean Glucose-6-phosphate dehydrogenase levels in relation to gestational age in the total population studied.

\begin{tabular}{|c|c|c|c|c|}
\hline Variable & N. & $\begin{array}{c}\text { Deficient } \\
(\%)\end{array}$ & $\begin{array}{c}\text { Normal } \\
(\&)\end{array}$ & $\begin{array}{c}\text { G6PD level } \\
(\mathrm{U} / \mathrm{gHb}) \\
(\text { mean } \pm \mathrm{SD})\end{array}$ \\
\hline \multicolumn{5}{|c|}{ Gestional age (weeks) } \\
\hline $27-29$ & 5 & $1(20)$ & $4(80)$ & $5.10 \pm 4.99$ \\
\hline $30-33$ & 50 & $14(28)$ & $36(72)$ & $4.23 \pm 2.5$ \\
\hline $34-36$ & 88 & $37(42)$ & $51(58)$ & $4.1 \pm 2.4$ \\
\hline $37-40$ & 430 & $163(38)$ & $267(62)$ & $4.0 \pm 2.5$ \\
\hline $41-42$ & 71 & $25(35.2)$ & $46(64.8)$ & $3.7 \pm 2.4$ \\
\hline
\end{tabular}

$\mathrm{F}=0.64, \mathrm{P}=0.64$

Table 2. Relationship between gestational age, glucose-6-phosphate dehydrogenase level and occurrence of jaundice.

\begin{tabular}{lccccc} 
Parameter & $\begin{array}{c}\text { Jaundice } \\
(\%)\end{array}$ & $\begin{array}{c}\text { N. Jaundice } \\
(\%)\end{array}$ & $\chi^{2}$ & P & RR \\
Gestational age & & & & & \\
Pre-term (n=143) & $86(61 \%)$ & $57(39 \%)$ & & & \\
Term $(\mathrm{n}=501)$ & $125(25 \%)$ & $376(75 \%)$ & 60.95 & 0.00001 & 2.41 \\
\hline
\end{tabular}

Gestational age and glucose-6-phosphate dehydrogenase status

27-36 weeks

\begin{tabular}{ccccc} 
deficient & $33(63.5 \%)$ & $19(36.5 \%)$ & & \\
normal & $53(58.2 \%)$ & $38(41.8 \%)$ & 0.19 & 0.66 \\
$37-42$ weeks & & & & \\
deficient & $78(41.5 \%)$ & $110(58.5 \%)$ & & \\
normal & $47(15 \%)$ & $266(85 \%)$ & 24.32 & 0.0000008 \\
\hline
\end{tabular}

Table 3. Mean duration of phototherapy (SD) and number of EBT performed in each gestational age group.

\begin{tabular}{lccc}
$\begin{array}{l}\text { Gestational age } \\
\text { (weeks) }\end{array}$ & N. & $\begin{array}{c}\text { Mean (SD) of } \\
\text { phototherapy (hours) }\end{array}$ & $\begin{array}{c}\text { N. babies } \\
\text { who had EBT performed }\end{array}$ \\
$27-29$ & 5 & $119.5 \pm 50.5$ & 1 \\
$30-33$ & 50 & $93.9 \pm 47.6$ & 8 \\
\hline $34-36$ & 88 & $23.3 \pm 37.1$ & 6 \\
$37-40$ & 430 & $6.7 \pm 23.5$ & 0 \\
\hline $41-42$ & 71 & $8.6 \pm 24.8$ & 0 \\
\hline
\end{tabular}

$F=123.34, P=0.000$ 
National Postgraduate College of Nigeria, 1983.

11. Lubchenco LA, Hansman C, Dressler M, Boyd E. Intrauterine growth as estimated from liveborn birth-weight data at 24 to 42 weeks of gestation. Pediatrics 1963;32: 793-800.

12. Ballard JL, Novak KK, Driver M. A simplified score for assessment of foetal maturity of newborn infants. J Pediatr 1979;95: 769 .

13. Bhutani VK, Johnson L, Sivieri EM. Predictive ability of a prediscahrge hour specific serum bilirubin for subsequent significant hyperbilirubinaemia in healthy term and near term newborns. Pediatrics 1999;103:6-14.

5. Effiong CE, Aimaku VE, Bienzle V, et al. Neonatal jaundice in Ibadan: Incidence, aetiological factors in babies born in hospitals. J Natl Med Assoc 1975;67:208-13.

6. Owa JA, Dawodu AH, Familusi JB. Kernicterus in Nigerian infants. W Afr $\mathrm{J}$ Med 1987;6:11-20.

7. Owa JA, Taiwo 0, Adebiyi JA0, Dogunro SA. Neonatal jaundice at Wesley Guild hospital Ilesha and Ife State Hospital Ile-Ife. Nig J Paediat 1989;16:23-30.

8. Slusher TM, Verman HJ, Mclaren DW, et al. Glucose-6-Phosphate dehydrogenase deficiency and carboxyhemoglobin concentrations associated with bilirubin related morbidity and death in Nigerian infants. J Pediatr 1995;126:102-8.

9. Effiong CE, Laditan AAO. Neonatal Jaundice in Ibadan : A study of cases seen in the outpatient clinic. Nig $\mathrm{J}$ Paediatr 1976;3:1-8.

10. Owa JA. Neonatal Jaundice in Ibadan. Observations on Aetiopathogenesis and Prevention. Dissertation presented to the

Rodwell VW editors. Haper's Biochemistry. 26th ed. Lange Medical Books/McGrawHill, New York, USA, 2003, pp 270-85.

16. Dean AG, Dean JA, Coulombier D. Epi info version 6.0. A word processing data base and statistics programme for public health on IBM compatible microcomputers. Atlanta Centre for Disease Control and Prevention. 1995.

17. Mesner 0, Hammerman C, Goldschimidt D, et al. Glucose-6-phosphate dehydrogenase activity in male premature and term neonates. Arch of Dis Child Fetal Neonatal Ed 2004;89:F555-7.

18. Hay Ko C, Pui-On Wong R, et al. Oxidative challenge and glucose-6-phosphate dehydrogenase activity of preterm and term neonatal red blood cells. Neonatology: Fetal and Neonatal Research 2009;96:96101.

19. Stoll BJ, Kliegman RM. Digestive System Disorders. In: RE Berhman, R KLiegman, HB Jenson (eds.) Nelson Textbook of Pediatrics. 17th ed. Philadelphia: WB Saunders, Philadelphia, USA, 2004, pp 588-98.

20. Porter ML, Dennis BL. Hyperbilirubinaemia in newborn. Am Fam Physician 2002; 65:599-606.

21. Owa JA, Dawodu AH. Neonatal jaundice among Nigerian preterm infants. West Afr J Med 1990;9:252-7.

22. Maisels MJ. Jaundice. In: MG MacDonald, MMK Seshia, MD Mullett (eds.) Neonatology Pathophysiology and Management of the newborn. $6^{\text {th }}$ ed. Lippincott Williams \& Wilkins, Philadelphia, USA, 2005, pp; 768841.

23. Wong RJ, Stevenson DK, Ahlfors CE, Vreman HJ. Neonatal Jaundice: Bilirubin physiology and clinical chemistry. Neo Reviews 2007;8:e58-67.
24. Onishi S, Kawade N, Itoh S. Postnatal development of urridine diphosphate glucuronyl transferase activity toward $\mathrm{s}$ bilirubin and 0-aminophenol in human liver. Biochem J 1979;194:705

25. Kawade N, Onishi S. the prenatal and postnatal development of UDP-glocuronyl transferase activity towards bilirubin and the effect of premature birth on this activity in the human liver. Biochem J 1981; 196:257.

26. Odell GB. Normal metabolism of bilirubin during neonatal life. In: Neonatal hyperbilirubinaemia. Grune \& Stratton, New York, USA, 1980, pp 42-9. 